\title{
Importância da inserção de grupo controle em ensaios utilizando animais de laboratório
}

\author{
Importance of inserting a control group in assays using \\ laboratory animals
}

Jussara Simmer Bravin'

Magno Maciel-Magalhães',* (D)

Yasmin da Silva Gomes

Pinheiro' (iD

Miguel Ângelo Brück

Gonçalves"

Fausto Klabund Ferraris'

Fábio Coelho Amendoeira' iD

I Instituto Nacional de Controle de Qualidade em Saúde (INCQS), Fundação Oswaldo Cruz (Fiocruz), Rio de Janeiro, RJ, Brasil

" Instituto Oswaldo Cruz (IOC), Fundação Oswaldo Cruz (Fiocruz) Rio de Janeiro, RJ, Brasil

\footnotetext{
* E-mail: magno.magalhaes@incqs.
} fiocruz.br

\section{RESUMO}

Introdução: $\mathrm{O}$ uso de animais de laboratório é fundamental em áreas em que ainda não podem ser substituídos na totalidade, como a toxicologia. Em estudos que se utilizam, para fins de comparação, apenas dados fornecidos pelos laboratórios de análises clínicas, na tentativa de reduzir o número de animais de um experimento, arrisca-se utilizar informações que não correspondem à realidade. Objetivo: Debater o uso de grupo controle em experimentos com animais. Método: Este artigo comparou valores hematológicos e bioquímicos de ratos da linhagem Wistar, obtidos em três biotérios de criação de diferentes estados brasileiros, com os resultados de animais provindos do Instituto de Ciência e Tecnologia em Biomodelos da Fundação Oswaldo Cruz, Rio de Janeiro, objetivando a discussão acerca da tomada de decisão sobre a inclusão de grupo controle em ensaios de toxicidade aguda oral. Resultados: Poucos foram os parâmetros que não apresentaram diferenças estatísticas, tais como: hemácia em fêmeas (duas referências), hemoglobina em fêmeas (uma referência) e machos (uma referência), hematócrito nos machos (duas referências) e hemoglobina corpuscular média nas fêmeas (duas referências), leucócitos nos machos (uma referência), creatinina e alanina aminotransferase (ALT) em todas as fêmeas. Conclusões: 0 uso do grupo controle se faz necessário quando valores analisados preliminarmente apresentam-se discrepantes daqueles tidos como referenciais da espécie.

PALAVRAS-CHAVE: Animais de Laboratório; Ratos Wistar; Experimentação Animal; Valores de Referência; Grupo Controle

\section{ABSTRACT}

Introduction: The use of laboratory animals is essential in areas where they cannot yet be completely replaced, such as toxicology. In studies that use, for comparison purposes, only data provided by the clinical analysis laboratories, in an attempt to reduce the number of animals in an experiment, there is the risk of using information that does not correspond to reality. Objective: Discuss the use of control groups in animals' experiments. Method: This article compared the hematological and biochemical values of rats of the Wistar strain, obtained in three breeding facilities in different Brazilian states, with the results of animals from the Institute of Science and Technology in Biomodels of the Oswaldo Cruz Foundation, Rio de Janeiro, aiming at the discussion about decision-making on the inclusion of a control group in acute oral toxicity trials. Results: Few parameters showed no statistical differences, such as red blood cells in females (two references), hemoglobin in females (one reference) and males (one reference), hematocrit in males (two references) and mean corpuscular hemoglobin in females (two references), leukocytes in males (a reference); creatinine and ALT in all females. Conclusions: It is concluded that the use of the control group is necessary, when values analyzed preliminarily differ from those considered as references of the species.

KEYWORDS: Laboratory Animals; Wistar Rats; Animal Experimentation; Reference Values; Control Group 


\section{INTRODUÇÃO}

O uso de animais de laboratório é parte integrante da pesquisa científica que possibilitou grande parte do desenvolvimento biomédico. Desde a antiguidade, com Aristóteles e Galeno em seus estudos de fisiologia comparada; no século XVIII, com Pasteur e Koch e seus estudos bacteriológicos com coelhos e cobaias; até a atualidade, com pesquisas no campo da nanotecnologia, ou mesmo sua utilização para fins regulatórios, o valor de sua contribuição à pesquisa científica é incalculável ${ }^{1}$.

Dentre as muitas áreas cuja necessidade de utilização dos animais de laboratório não pode ser ainda substituída em sua totalidade, destaca-se a área de toxicologia, tanto para a fase de desenvolvimento de novos produtos - por exemplo: medicamentos - quanto para a fase de processos regulatórios e sua validação $0^{2,3}$.

No Brasil, a Agência Nacional de Vigilância Sanitária (Anvisa) é o órgão governamental responsável pela regulamentação de novos fármacos, utilizando-se de documentos de agências reconhecidas pela vigilância sanitária de medicamentos como a Food and Drug Adminstration (FDA) e de organizações de interesse na área, tais como: Internation Council on Harmonisation (ICH), Organisation for Economic Co-operationand Development (OECD) e World Health Organization (WHO), visando uma maior harmonização com a regulamentação internacional ${ }^{4}$.

A Anvisa, em suas atribuições de registro de medicamentos e análise de pedidos de patentes relacionados a produtos e a processos farmacêuticos, em atuação conjunta com o Instituto Nacional da Propriedade Industrial (INPI), utiliza-se da Resolução de Diretoria Colegiada (RDC) $n^{\circ} 60$, de 10 de outubro de $2014^{4}$, que instrui sobre a obrigatoriedade da apresentação de relatório dos seguintes ensaios não clínicos para o registro de novos medicamentos: toxicidade aguda, subaguda e crônica, toxicidade reprodutiva, atividade mutagênica/genotóxica e potencial oncogênico.

Os ensaios não clínicos, pré-clínicos ou de Fase 0 precedem os testes em humanos, por fornecerem dados importantes e confiáveis para a continuidade da pesquisa clínica ${ }^{5}$, sendo a avaliação da toxicidade oral aguda o primeiro teste não clínico in vivo a ser realizado com o objetivo de determinar o potencial de novas substâncias e produtos de causar danos à saúde humana. São investigados parâmetros para identificar o potencial tóxico em órgãos específicos, predizer a toxicocinética e a relação dose-resposta, gerando informações suficientemente importantes para que se justifique a continuidade das pesquisas ${ }^{6}$.

Para o registro de novos fármacos, deve-se apresentar, como relatório inicial junto a Anvisa, os testes designados no documento "Guia para a Condução de Estudos Não Clínicos de Segurança Necessários ao Desenvolvimento de Medicamentos", que estabelece a utilização mínima de animais, a fim de não comprometer a obtenção e a confiabilidade de informações referentes à segurança da substância a ser testada ${ }^{7,8}$.

O Conselho Nacional de Controle de Experimentação Animal (CONCEA), em sua Resolução Normativa (RN) n 18, de 24 de setembro de $2014^{\circ}$, em seu Art. $1^{\circ}$ reconhece o uso de métodos alternativos validados, que tenham por finalidade a redução, a substituição ou o refinamento do uso de animais em atividades de pesquisa, nos termos da Lei $n^{\circ} 11.794$, de 8 de outubro de $2008^{10}$, e cita o guia 420 da OECD ${ }^{11}$ como um método alternativo, por reduzir o número de animais nos testes de toxicidade oral aguda.

Tanto o guia da Anvisa como o da OECD não sugerem o uso de grupo controle, devendo-se então utilizar os padrões fisiológicos estabelecidos para a(s) espécie(s) empregada(s) no teste, de acordo com a necessidade pontual da avaliação. Diversos autores apontam que os animais experimentais não se comportam do mesmo modo, nas condições a que estão submetidos, nos diferentes países onde são mantidos em cativeiro, e que, de forma geral, os valores dos parâmetros fisiológicos dos animais de experimentação são determinados por países com longa tradição de manutenção de biotérios e permanecem como constantes para os animais de uma mesma linhagem no mundo ${ }^{1,12,13}$.

Alguns autores, ao realizarem um estudo-piloto, observaram que os resultados obtidos nos grupos experimentais diferiam estatisticamente dos padrões estabelecidos para as linhagens utilizadas. A inserção do grupo controle para as mesmas comparações indicou que não havia diferenças estatísticas entre os animais testados e o grupo controle, e que o próprio grupo controle era estatisticamente diferente dos padrões estabelecidos para as linhagens utilizadas. A tomada de decisão contra a continuidade dos próximos testes toxicológicos poderia ter sido desastrosa se os grupos experimentais fossem comparados apenas às referências bibliográficas, conforme os guias utilizados, pois haveria a condenação de produtos de extrema valia aos futuros usuários ${ }^{14,15}$.

Desde a publicação do livro Principles of Human Experimental Thecnique em 1959, dos biólogos Russel e Burch, que propuseram o princípio dos 3 R: Replace (substituir), Refine (refinar) e Reduce (reduzir), há a orientação para as pesquisas que utilizam animais em experimento, que o façam de forma adequada; com o refinamento das técnicas objetivando evitar a dor e o sofrimento desnecessários; a substituição quando houver métodos validados, e a redução do número de animais/grupo experimental de forma a não comprometer o estudo realizado ${ }^{16,17,18}$.

No entanto, deve-se ter em mente que ainda não é possível a substituição por modelo não animal de alguns testes, tais como: toxicidade reprodutiva e crônica; cinética, metabolismo, dentre outros; o que impulsiona os condutores de pesquisas científicas, que utilizam animais de laboratórios, a utilizá-los de maneira mais eficiente, conforme os preceitos éticos ${ }^{2,18}$.

As avaliações hematológicas e bioquímicas são de extrema valia nos testes toxicológicos, pois fornecem dados sobre a homeostase do animal frente ao desafio imposto. A inclusão de um grupo controle pode fornecer dados de grande valor como ponto de partida para diversos estudos, possibilitando a obtenção de resultados confiáveis sobre estes parâmetros ${ }^{12,19}$. 
O objetivo deste artigo foi comparar valores hematológicos e bioquímicos de ratos da linhagem Wistar, em três biotérios de criação de estados distintos do Brasil, com os resultados obtidos da colônia de ratos Wistar, da Fundação Oswaldo Cruz (Fiocruz), Rio de Janeiro, utilizados como grupo controle em ensaios de toxicidade oral aguda. Com base nesses dados, buscou-se levantar a discussão sobre a necessidade de inclusão de grupo controle nos guias de protocolos experimentais de toxicidade em roedores, tais como os guias da OECD.

\section{MÉTODO}

Foram analisados os resultados dos seguintes biotérios de criação: Universidade de Tiradentes (UNIT) ${ }^{19}$, Universidade Federal de Sergipe (UFSE) ${ }^{12}$ e Universidade Federal da Paraíba (UFPB) ${ }^{20}$, cujas informações sobre o status sanitário dos animais testados dos referidos trabalhos resumem-se a "adultos, normais e saudáveis"; bem como a junção de dois desenhos experimentais realizados do Instituto de Controle de Qualidade em Saúde (INCQS) na Fiocruz ${ }^{14,15}$, que utilizaram os animais do Biotério de Criação do Instituto de Ciências e Tecnologia de Biomodelos (ICTB) da mesma fundação. Ambos os estudos analisados foram realizados utilizando ratos Wistar do sexo feminino, todos saudáveis ao início do experimento, e criados em biotério de criação e experimentação de status sanitário definido como convencional. Ademais, o ICTB fornece anualmente um relatório sanitário das colônias de roedores fornecidos por este Instituto para o restante da Fiocruz.

Analisaram-se os seguintes parâmetros hematológicos: hemácias (RBC), hemoglobina (HGB), hematócrito (HCT), volume corpuscular médio (VCM), hemoglobina corpuscular média $(\mathrm{MCH})$, concentração de hemoglobina corpuscular média ( $\mathrm{CHCM})$, contagem de leucócitos (WBC) e plaquetas (PLAQ). Foram avaliados os seguintes parâmetros bioquímicos: glicose, ureia, creatinina, albumina, aspartato aminotransferase (AST), alanina aminotransferase (ALT), fosfatase alcalina, colesterol e proteínas totais. Para cada parâmetro avaliado, os valores foram expressos em média e erro-padrão (EP). Todos os trabalhos analisados informaram as condições de alojamento, ingesta alimentar e hídrica, ciclo circadiano e temperatura aos quais os animais foram submetidos, bem como idade e/ou peso; e sexo. Informaram também a forma como foi realizado o procedimento de coleta de sangue e o método de processamento das amostras. E referenciaram suas respectivas licenças de comitês de ética ao uso de animais de experimentação.

Para a análise estatística, foi utilizado o programa Prisma $3^{\oplus}$, considerando estatisticamente significativos os valores de p inferiores a 0,05.

\section{RESULTADOS}

O resultado analisado dos valores dos parâmetros hematológicos está demonstrado no Quadro 1, e dos parâmetros bioquímicos no Quadro 2. De forma geral, observou-se que a maioria foi diferente estatisticamente uns dos outros.

$\mathrm{Na}$ avaliação hematológica, o parâmetro RBC do grupo das fêmeas da referência $n^{\circ} 2$ e da referência $n^{\circ} 4$ não foi estatisticamente diferente. No parâmetro HGB, não houve diferenças estatísticas no grupo de fêmeas da referência $n^{\circ} 2$ e no grupo de machos da referência $n^{\circ} 3$. No parâmetro $\mathrm{HCT}$, não houve diferença estatística no grupo de machos da referência $n^{\circ} 1$ e na referência $n^{\circ} 2$. No parâmetro $M C H$ não houve diferença estatística no grupo de fêmeas da referência $n^{\circ} 1$ e na referência $n^{\circ} 3$. No parâmetro WBC, apenas o grupo de machos da referência $n^{\circ}$ 3 não foi estatisticamente diferente.

Nos parâmetros da avaliação bioquímica, os valores do parâmetro creatinina no grupo de fêmeas em todas as referências analisadas, não foram estatisticamente diferentes uns dos outros. Os valores do parâmetro ALT no grupo das fêmeas em todas as referências analisadas também não apresentou diferenças estatísticas entre si.

\section{DISCUSSÃO}

Em um protocolo experimental, o animal de laboratório precisa ser considerado como um "reagente biológico", conforme Andersen et al. ${ }^{21}$, pois responderá a diversos fatores físicos, químicos e biológicos que existem dentro e fora do ambiente onde se encontram.

Tudo o que o circunda pode exercer influências nas características deste "reagente". Esta interferência refletirá diretamente na resposta do animal aos experimentos, visto que o seu organismo tentará voltar a homeostase (condição de equilíbrio e ou normalidade) após qualquer intervenção, pois, até mesmo no trato de rotina, onde uma simples manipulação para troca de caixa com uma contenção física mal executada pode afetar esses parâmetros fisiológicos tão importantes para a homeostase ${ }^{22}$.

A manutenção dessas condições ambientais em biotérios estáveis, tanto ao que se refere às edificações quanto aos procedimentos operacionais padronizados utilizados na rotina, irá permitir resultados das pesquisas os mais fidedignos possíveis, uma vez que poderemos encontrar resultados diversos na experimentação animal em parâmetros experimentais praticados em condições ambientais de biotérios quando não controlados ${ }^{21,13,22,23}$.

A alimentação tem forte influência sobre os experimentos, visto que McCabe et al. ${ }^{24}$, em seus estudos, observaram que os componentes microbianos intestinais estão intimamente relacionados com o perfil imunológico do animal, fazendo a interface intestino-sistema imune e, consequentemente, nas respostas de homeostase que o animal faz frente ao desafio proposto no delineamento experimental. Para tal, a ingestão de alimentos de forma adequada é um fator fundamental à experimentação animal, no intuito de seu potencial genético, de crescimento, de reprodução, de longevidade e de resposta a estímulos experimentais ${ }^{23}$.

Conforme Bravin ${ }^{14}$ e Maciel-Magalhães et al. ${ }^{15}$ observaram em seus estudos, a ração comercial utilizada no biotério de experimentação, cuja origem era a mesma do biotério de criação daquela Instituição, não possuía balanceamento apropriado dos nutrientes estabelecidos para ratos da linhagem Wistar; seja em quantidades excessivas como o sódio e o cálcio, seja ausente de informações como potássio. E esse desbalanceamento foi refletido nas análises bioquímicas dos animais tanto dos grupos experimentais como dos respectivos grupos controle ${ }^{13,23}$. 

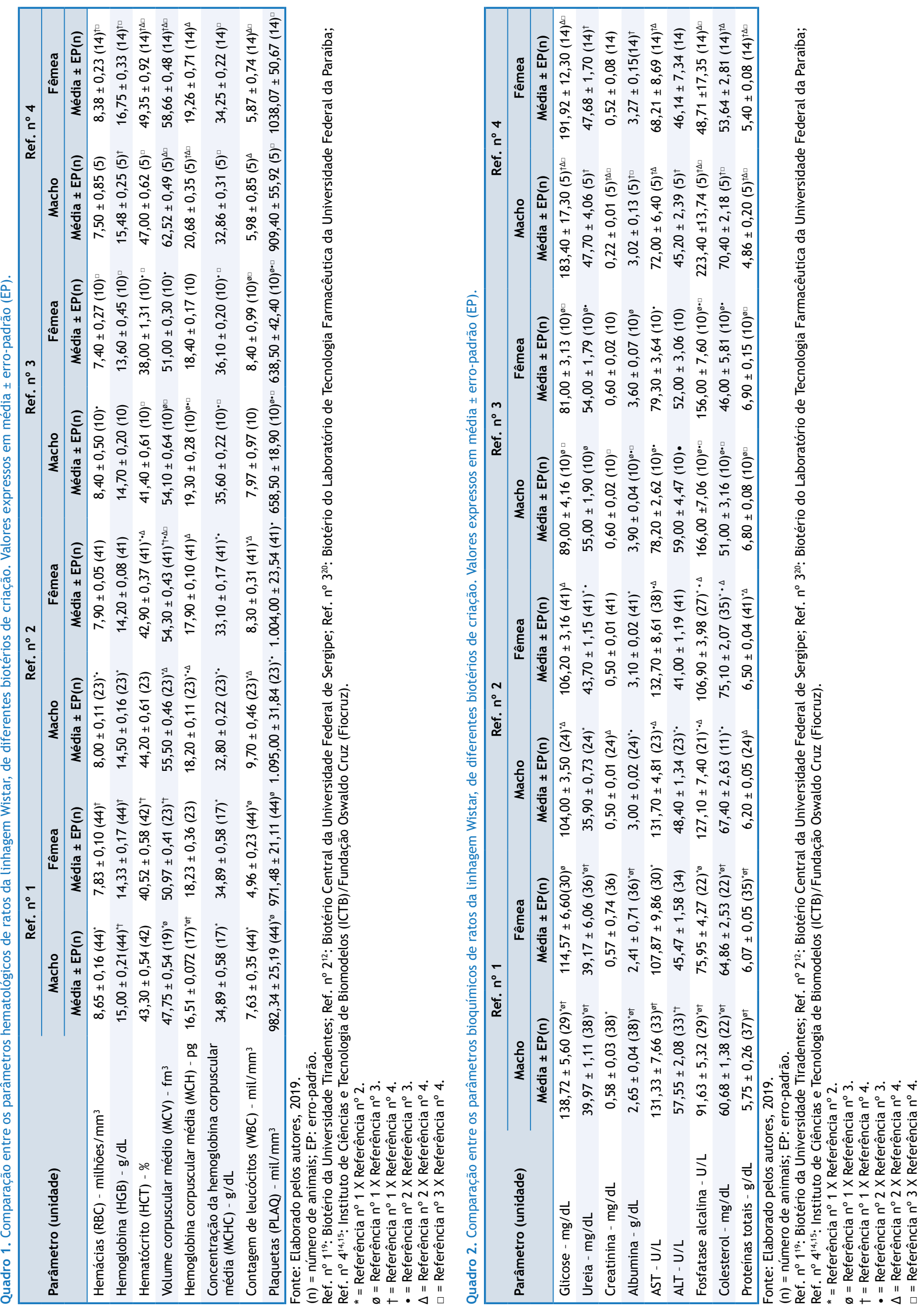
Dias e Amaral Junior ${ }^{25}$, após analisarem amostras de três marcas de ração comercial para animais de laboratório, concluíram pela ausência de componentes fundamentais como: lisina, ferro, magnésio, por exemplo; que comprometem diretamente o crescimento.

De acordo com Moura ${ }^{26}$, há a necessidade de conhecimento das exigências nutricionais dos animais de laboratório sob as condições da realidade em que se encontram mantidos, devendo haver um acordo entre os fabricantes e as instituições, com o intuito de que os alimentos ofertados atendam a demandas efetivas da espécie.

A determinação do consumo de ração é muito importante nos estudos de segurança de produtos com finalidade terapêutica, uma vez que a ingestão adequada é essencial para a manutenção fisiológica do animal e para se obter resposta adequada ao experimento realizado ${ }^{7,13}$.

Conforme cita Diniz et al. ${ }^{20}$, a determinação genética do animal também pode influenciar as diferenças entre parâmetros tidos como fisiológicos, tendo em vista as diferenças entre as linhagens de uma mesma espécie.

Um aspecto importante a ser enfatizado, de acordo com Lima et al. ${ }^{19}$, são as diversas formas de processamento das amostras sanguíneas, bem como o local anatômico da coleta (punção cardíaca $x$ artéria mesentérica $x$ plexo orbital), e ainda o tipo de medicamento utilizado para a realização da contenção química, o que pode influenciar fortemente as diferenças estatísticas encontradas nesta avaliação.

De acordo com Melo et al. ${ }^{12}$, ao se utilizar dados de literatura ou referências bibliográficas de instituições com longa tradição em criação de animais de laboratório, e admitidos como constantes, com o intuito de se reduzir o número de animais em um experimento/ensaio, o pesquisador corre o risco de utilizar dados que não correspondem com a realidade, sendo de suma importância que cada instituição estabeleça seus próprios parâmetros, levando-se em consideração o tipo de automação laboratorial utilizada para as análises dos mesmos.

Bravin ${ }^{14}$ e Maciel-Magalhães et al. ${ }^{15}$, durante o encaminhamento dos seus trabalhos, debateram acerca do uso do grupo controle, de forma a dar mais credibilidade aos resultados obtidos, ainda que o CONCEA em sua RN n ${ }^{\circ} 18 / 2014^{\circ}$, em seu Art. $1^{\circ}$ reconheça o uso de métodos alternativos validados, que tenham por finalidade a redução, a substituição ou o refinamento do uso de animais em atividades de pesquisa, nos termos da Lei $\mathrm{n}^{\circ} 11.794 / 2008^{10}$ e cita o guia 420 da OECD ${ }^{11}$ como um método alternativo, por reduzir o número de animais nos testes.

Em tempo, Bravin ${ }^{14}$ cita em seu estudo que tantos os guias da Anvisa como os da OECD ${ }^{11}$ não indicam a necessidade de grupo controle, porém a sua inclusão foi fundamental para uma comparação pontual da molécula testada, uma vez que as diferenças encontradas com os dados de literatura seriam consideradas estatisticamente relevantes, caso não houvesse esse grupo.

\section{CONCLUSÕES}

Com o presente trabalho, é possível inferir que o uso do grupo controle se faz necessário para fins de melhor comparação, especialmente quando os valores analisados em estudo-piloto aparentam ser discrepantes em relação aos tidos como referenciais para determinada espécie, sejam estes os encontrados na literatura especializada, ou os fornecidos pelo laboratório onde os materiais clínicos foram analisados.

\section{REFERÊNCIAS}

1. Robinson NB, Krieger K, Khan FM, Huffman W, Chang $M$, Naik A et al. The current state of animal models in research: a review. Int J Surg. 2019;72:9-13. https://doi.org/10.1016/j.ijsu.2019.10.015

2. Silva CC, Oliveira CBN, Carneiro PS, Marengo EB, Mattos KA, Almeida RSC et al. Métodos alternativos para a detecção de pirogênios em produtos e ambientes sujeitos a vigilância sanitária: avanços e perspectivas no Brasil a partir do reconhecimento internacional do teste de ativação de monócitos. Vigil Sanit Debate. 2018;6(1):137-49. https://doi.org/10.22239/2317-269x.01082

3. Scholz S, Sela E, Blaha L, Braunbeck T, Galay-Burgos $M$, García-Franco $M$ et al. A european perspective on alternatives to animal testing for environmental hazard identification and risk assessment. Regul Toxicol Pharmacol. 2013;67(3):506-30. https://doi.org/10.1016/j.yrtph.2013.10.003

4. Agência Nacional de Vigilância Sanitária - Anvisa. Resolução RDC N ${ }^{\circ} 60$, de 10 de outubro de 2014. Dispõe sobre os critérios para a concessão e renovação do registro de medicamentos com princípios ativos sintéticos e semissintéticos, classificados como novos, genéricos e similares, e dá outras providências. Diário Oficial União. 11 out 2014.

5. Agência Nacional de Vigilância Sanitária - Anvisa. Guia para a condução de estudos não clínicos de toxicologia e segurança farmacológica necessários ao desenvolvimento de medicamentos: gerência de avaliação de segurança e eficácia (Gesef). Brasília: Agência Nacional de Vigilância Sanitária; 2013.

6. Goldin JR. A avaliação da investigação científica de novas drogas: a importância da caracterização adequada das fases da pesquisa. Rev HCPA. 2007;27(1):66-73.

7. Santos T. Teste toxicológico pré-clínico para o desenvolvimento da vacina anti-helmíntica baseada no antígeno r-sm14 de Schistosoma mansoni [dissertação]. Rio de Janeiro: Fundação Oswaldo Cruz; 2012[acesso 28 set 2019]. Disponível em: https: / / www.arca. fiocruz.br/handle/icict/7898

8. Freires IA, Sardi JC, Castro RD, Rosalen PL. Alternative animal and non-animal models for drug discovery and development: bonus or burden? Pharm Res. 2017;34(4):681-6. https://doi.org/10.1007/s11095-016-2069-z 
9. Ministério da Ciência, Tecnologia e Inovação (BR). Resolução normativa $N^{\circ} 18$, de 24 de setembro de 2014. Reconhece métodos alternativos ao uso de animais em atividades de pesquisa no Brasil, nos termos da resolução normativa $\mathrm{N}^{\circ}$ 17, de 3 de julho de 2014, e dá outras providências. Diário Oficial União. 25 set 2014.

10. Brasil. Lei $N^{\circ} 11.794$, de 8 de outubro de 2008. Regulamenta o inciso 7 do paragrafo 1 do artigo 225 da constituição federal, estabelecendo procedimentos para o uso científico de animais; revoga a lei $N^{\circ} 6.638$, de 8 de maio de 1979; e dá outras providências. Diário Oficial União. 9 out 2008.

11. Organisation for Economic Co-operation and Development - OECD. OECD guideline for testing of chemicals. Paris: Organisation for Economic Co-cperation and Development; 2001[acesso 1 set 2018]. Disponível em: http://ntp.niehs. nih.gov/iccvam/suppdocs/feddocs/oecd/oecd_gl423.pdf

12. Melo MG, Dória GAA, Serafini MR, Araújo AAS. Valores de referência hematológicos e bioquímicos de ratos (Rattus novergicus) linhagem Wistar provenientes do biotério central da universidade federal de Sergipe. Sci Plena. 2012;8(9):1-6.

13. Lapchik VV, Mattaraia VM, Ko GM. Cuidado e manejo de animais de laboratório. 2a ed. São Paulo: Atheneu; 2017.

14. Bravin JS. Avaliação da toxicidade oral aguda de um análogo de mexiletina candidato a fármaco antiasmático [dissertação]. Rio de Janeiro: Fundação Oswaldo Cruz; 2016.

15. Maciel-Magalhães M, Medeiros RJ, Bravin JS, Patricio BFC, Rocha H, Almeida ECP et al. Evaluation of acute toxicity and copper accumulation in organs of Wistar rats, 14 days after oral exposure to copper oxide (II) nano- and microparticles. J Nanopart Res. 2020;22(2). https: / /doi.org/10.1007/s11051-019-4721-0

16. Russell WMS, Burch KL. The principles of humane experimental technique. London: Universities Federation for Animal Welfare; 1992[acesso 24 set 2019]. Disponível em: http://altweb.jhsph.edu/

17. Damy SB, Camargo RS, Chammas R, Figueiredo LFP. Aspectos fundamentais da experimentação animal: aplicações em cirurgia experimental.
Rev Assoc Med Bras. 2010;56(1):103-11. https://doi.org/10.1590/S0104-42302010000100024

18. Zane P, Gieschen H, Kersten E, Mathias N, Ollier $C$, Johansson $\mathrm{P}$ et al. In vivo models and decision trees for formulation development in early drug development: a review of current practices and recommendations for biopharmaceutical development. Eur J Pharm Biopharm. 2019;142:222-31. https://doi.org/10.1016/j.ejpb.2019.06.010

19. Lima CM, Lima AK, Melo MGD, Dória GAA, Serafini MR, Albuquerque Júnor RLC et al. Valores de referência hematológicos e bioquímicos de ratos (Rattus novergicus linhagem Wistar) provenientes do biotério da universidade Tiradentes. Sci Plena. 2014;10(3):1-9.

20. Diniz MFFM, Medeiros IA, Santos HB, Oliveira KM, Vasconcelos THC, Aguiar FB et al. Padronização dos parâmetros hematológicos e bioquímicos de camundongos swiss e ratos Wistar. Rev Bras Cienc Saude. 2006;10(2):171-6.

21. Andersen $M L$, organizador. Princípios éticos e práticos do uso de animais de experimentação. São Paulo: Universidade Federal de São Paulo; 2004.

22. Majerowicz J. Boas práticas em biotérios e biossegurança. Rio de Janeiro: Interciência; 2008.

23. Andrade A, Pinto SC, Oliveira RS. Animais de laboratório: criação e experimentação. Rio de Janeiro: Fundação Oswaldo Cruz; 2002.

24. McCabe L, Britton RA, Parameswaran N. Prebiotic and probiotic regulation of bone health: role of the intestine and its microbiome. Curr Osteoporos Rep. 2015;13(6):363-71. https://doi.org/10.1007/s11914-015-0292-x

25. Dias HLM, Amaral Junior SCA. Uma análise comparativa e descritiva de rações comerciais utilizadas para animais de laboratório. Rev Soc Bras Cienc Anim Lab. 2014;2(4):273-80.

26. Moura AMA. Nutrição de roedores de laboratório: paradigmas e desafios. Rev Soc Bras Cienc Anim Lab. 2014;2(4):288-96.

\section{Agradecimentos}

Os autores deste trabalho gostariam de agradecer, primeiramente, a todos os animais que dão suas vidas ao melhoramento da ciência. Também agradecem ao Instituto de Ciência e Tecnologia em Biomodelos (ICTB) da Fiocruz, pelos animais utilizados nos trabalhos e pelos dados laboratoriais obtidos em sua plataforma de análises clínicas.

\section{Contribuição dos Autores}

Bravin JS, Ferraris FK, Amendoeira FC - Concepção, planejamento (desenho do estudo), aquisição, análise, interpretação dos dados e redação do trabalho. Maciel-Magalhães M, Pinheiro YSG, Gonçalves MAB - Aquisição, análise, interpretação dos dados e redação do trabalho. Todos os autores aprovaram a versão final do trabalho. 